\title{
Can Electrical Conductivity Predict Seed Germination of Three Pinus Species?
}

\author{
By I. Takos*), G. Varsamis, T. Merou and C. Alexiou \\ Institute of Technology, Annex of Drama, Department of Forestry \& Natural Environment Management, \\ $1^{\text {st }}$ kill. Drama-Kalampaki, 66100 Drama, Greece
}

(Received 24 ${ }^{\text {th }}$ January 2012)

\begin{abstract}
The potential of using the electrical conductivity method to predict seed germination of Pinus pinea, $P$. halepensis and P. nigra was investigated. Seed lots with low germination presented high conductivity values while those with high germination presented lower conductivity values after 48 hours of incubation. Based on linear regression analysis models with outlier remove analysis, high regression coefficients were obtained suggesting that it is possible to predict germination of the specific species through a quick electrical conductivity test.
\end{abstract}

Key words: Electrical conductivity, germination, Pinus pinea, Pinus nigra, Pinus halepensis.

\section{Introduction}

Germination tests under laboratory conditions are widely used in order to determine the maximum germination potential of a seed lot. However, they are often time consuming as they may require either periods of measurements longer than two weeks or long pretreatment periods such as stratification (EsCUDERo et al., 2002; KRUGMan and Jenkinson, 2008). This has led to the development of rapid quality tests such as the Electrical Conductivity Test. Although electrical conductivity has been adopted as an indirect seed vigour test to compare and discriminate different seedlots with approximately the same germination percentage, it can be used as a quick alternative to the germination test however (BonNer et al., 1994; SǿRENSEN et al., 1996). This method relies on the integrity of the seed cellular membranes. Seeds of low quality have usually more disorganized their membranes and present high flow of electrolytes from their interior which results in high electrical conductivity and commonly coincides with low germination. On the other hand high quality seeds are able to repair and reorganize their membranes at a faster rate than the low quality ones and thus they present lower electrolyte leakage (HAMPTON and TEKRONY, 1995). The relationship between electrical conductivity and germination of seeds has been studied in many agricultural and forage species as well as in few forest species (e.g., SAHLÉN and GJELSVIK, 1993; PEKŞEN et al., 2004).

The aim of this study was to examine the possibility of using the electrical conductivity method as a quick test

\footnotetext{
*) Corresponding author: IOANNIS TAKos.

E-mail: itakos@teikav.edu.gr
}

in order to predict germination in three Pinus species (P. pinea L., P. halepensis Mill and P. nigra J.F. Arnold).

\section{Materials and Methods}

Fifteen seed lots were used per species, which had been provided by the Greek National Forest Seed Storage Service in 2010 and had been collected from a broad range of origins. All seed lots were kept at $4{ }^{\circ} \mathrm{C}$ for one week until the beginning of the experiment. Prior to the experimental procedures, initial seed moisture content was determined by the oven method at $105 \pm 3{ }^{\circ} \mathrm{C}$ for $24 \mathrm{~h}$ and expressed on fresh weight basis (AOSA, 2002). The moisture content test was performed in order to calculate the seed dry weight (g) used for the expression of the results from the electrical conductivity test (SǿRENSEN et al., 1996).

To assess germination, 4 replications of 100 seeds from each seed lot for every species were tested following appropriate pretreatments. For $P$. pinea, seeds were immersed in water for $24 \mathrm{~h}$ prior to germination (YouNG and Young, 1992). Pinus nigra seeds were cold stratified at $5{ }^{\circ} \mathrm{C}$ for a period of 2 months prior to germination. No pre-germination treatment was applied to $P$. halepensis seeds (KRUGMAN and JENKInson, 2008). Seeds were then placed in germinators set at daily cycles of $25^{\circ} \mathrm{C}$ for $8 \mathrm{~h} /$ light and $16^{\circ} \mathrm{C}$ for $16 \mathrm{~h} /$ dark. The presence of a 2 mm-long radicle was the criterion for germination. Based on germination results, seed lots were grouped into four quality classes according to their germination percentage as it has been proposed for Pinus $s p$. and Picea abies by SǿREnsen et al. (1996) and Bonner (1991). For each grouped seedlot, we assigned its conductivity value and found the range of conductivity values for each quality class.

The electrical conductivity test was performed according to methods described by AOSA (2002) and SǿRENSEN et al. (1996). Conductivity measurements of seed leakage were performed using an EC 215 conductivity meter (Hanna Instruments, Inc.) and expressed as $\mu \mathrm{Sxcm}^{-1} \mathrm{xg}^{-1}$ (AOSA, 2002). Four replications of 50 seeds from each seed lot for every species were used for the conductivity test. It should be mentioned here that in Pinus pinea no available data exist for the medium seed quality class as none of the used lots presented germination percentage within the corresponding range (65-85\%) (Table 1).

Regression analysis was performed by considering conductivity as the predictor variable and germination 
Table 1. - Relationship between germination and electrical conductivity of three Pinus species grouped into four quality classes and the resulting best regression predictor models.

\begin{tabular}{|c|c|c|c|c|c|c|}
\hline Species & $\begin{array}{c}\text { Seed } \\
\text { quality class }\end{array}$ & $\begin{array}{c}\text { Germination } \\
(\%)\end{array}$ & $\begin{array}{c}\text { Electrical } \\
\text { conductivity } \\
\left(\mu \mathrm{s} \times \mathrm{cm}^{-1} \times \mathbf{g}^{-1}\right)\end{array}$ & $\begin{array}{l}\text { Transformed linear } \\
\text { regression model }\end{array}$ & $\begin{array}{c}\text { Regression } \\
\text { Coefficient } \\
\left(R^{2}\right)\end{array}$ & $\begin{array}{c}\text { SE error } \\
\text { of } \\
\text { estimate }\end{array}$ \\
\hline \multirow{4}{*}{$\begin{array}{l}\text { Pinus } \\
\text { pinea }\end{array}$} & High & $85-100$ & $<10$ & \multirow{4}{*}{$\begin{array}{c}Y=5.216-0.060 \times X \\
Y=\ln (y), \quad X=x\end{array}$} & \multirow{4}{*}{0.85} & \multirow{4}{*}{0.837} \\
\hline & Medium & 65-85 (ND) & $\mathrm{ND}^{\dagger}$ & & & \\
\hline & Low & $40-65$ & $38-59$ & & & \\
\hline & Poor & $<40$ & $>59$ & & & \\
\hline \multirow{4}{*}{$\begin{array}{c}\text { Pinus } \\
\text { halepensis }\end{array}$} & High & $85-100$ & $<16$ & \multirow{4}{*}{$\begin{array}{c}Y=4.716-0.024 \times X \\
Y=\ln (y), \quad X=x\end{array}$} & \multirow{4}{*}{0.90} & \multirow{4}{*}{0.219} \\
\hline & Medium & $65-85$ & $16-23$ & & & \\
\hline & Low & $40-65$ & $23-46$ & & & \\
\hline & Poor & $<40$ & $>46$ & & & \\
\hline \multirow{4}{*}{$\begin{array}{l}\text { Pinus } \\
\text { nigra }\end{array}$} & High & $85-100$ & $<19$ & \multirow{4}{*}{$\begin{array}{c}Y=5.197-0.335 \times X \\
Y=\ln (y), \quad X=x\end{array}$} & \multirow{4}{*}{0.93} & \multirow{4}{*}{0.498} \\
\hline & Medium & $65-85$ & $19-45$ & & & \\
\hline & Low & $40-65$ & $45-60$ & & & \\
\hline & Poor & $<40$ & $>60$ & & & \\
\hline
\end{tabular}

\footnotetext{
$\dagger$ No data available in this category.

$\$$ The symbols $y, x$ represent the experimental values for germination and conductivity respectively while the symbols $Y, X$ represent the transformed values in the linear models.
}

as the dependent variable. Both variables were checked for normality and homogeneity. Outlier values were removed. Because no linear relationship was observed between the two variables, different non-linear curve fitting models were estimated and transformed non-linear variables were used in linear models. The suitability of the transformed models was checked using residuals scatterplots with the predictor variable conductivity (BLACK, 2006). Additionally, a complete residual analysis was performed. For each species, only the best fit model is presented.

\section{Results and Discussion}

Results clearly pointed to a relationship between the two tested variables, as indicated by the high regression coefficients of the best predictor models in all the studied species (Table 1).

Due to the number of lots per species that were used in the present experiment, we found it useful to group the lots in categories in order to be more easily reviewed. So we separated four quality classes of seeds (High, Medium, Low, Poor) according to germination percentage as this discrimination has already been applied in Pinus sp. as well as in Picea abies (BonNER, 1991; SǿRENSEN et al., 1996). It was observed that seedlots grouped in the same class had conductivity values within a specific range. Thus, the same quality classes resulted in comparable conductivity for all tested species. Separate regression models were developed for each species because of differences in their seed characteristics (e.g. different seed dry mass). From Table 1, it can be seen that the lower the germination percentage was, the higher the electrical conductivity and vice versa. Higher conductivity from seeds with lower germination was due to differences in electrolyte leakage, most probably caused by differences in the structural integrity of cellular membranes (SǿRENSEN et al., 1996; KARRFALT, 2008). On the other hand, seeds with higher germination had lower conductivity values, probably due to the greater ability to repair and reconstitute their membranes which stops leakage (SǿRENSEN et al., 1996).

The usefulness of the electrical conductivity test as quick quality test has been widely recognized (BONNER et al., 1994; HAMPTON and TEKRONY, 1995), while its potential relationship to germination has been investigated not only in Pinus sp. but also in a further number of woody species (e.g. GonZales et al., 2011; GUANG-WU and TAI-LIN, 2012). The relatively easiness of the electrical conductivity method makes this test transferable to many woody species.

In conclusion, low conductivity values in $P$. pinea, $P$. halepensis and $P$. nigra were associated with high germination percentages. It must be mentioned here that this finding does not assume that the electrical conductivity must replace the standard germination test, but when there is a time limit and quick results are expected, it can be useful as a quick alternative. Regression analysis and the associated high regression coefficients of the best models indicated that the variation in germination can be successfully predicted by conductivity measurements. This suggests that the proposed models of this study can be used to predict the germination percentage in the specific Pinus species by evaluating seed leakage conductivity values. Finally, further studies concerning the examination of relationship between germination and conductivity under a broad range of testing conditions are needed for standardization of the conductivity method as a quick test to predict seed germination.

\section{References}

AOSA (2002): Seed Vigor Testing Handbook. Association of Official Seed Analysts, Lincoln, NE, USA.

Bonner, F. T. (1991): Leachate Conductivity: A Rapid Nondestructive Test for Pine Seed Quality. Tree Planter's Notes 42(2): 41-44. 